\title{
Knowledge and Perception of Breast Cancer among Women of Various Ethnic Groups in the State of Penang: A Cross-Sectional Survey
}

\author{
Muhammad Abdul Hadi ${ }^{a} \quad$ Mohamed Azmi Hassali ${ }^{b}$ Asrul Akmal Shafie ${ }^{b}$ \\ Ahmed Awaisu ${ }^{c}$ \\ ${ }^{a}$ Department of Clinical Pharmacy, Faculty of Pharmacy, Universiti Teknologi MARA, Shah Alam, and Disciplines of \\ ${ }^{b}$ Social and Administrative Pharmacy and ${ }^{C}$ Clinical Pharmacy, School of Pharmaceutical Sciences, Universiti Sains \\ Malaysia, Penang, Malaysia
}

\section{Key Words}

Breast cancer $\cdot$ Knowledge $\cdot$ Perception $\cdot$ Women $\cdot$ Malaysia

\begin{abstract}
Objective: The objective of this study was to assess and compare the knowledge and perception of breast cancer among women of various ethnic groups in the state of Penang. Subjects and Methods: A cross-sectional survey was conducted from February 5 to March 15, 2008. 384 participants were conveniently selected and interviewed face to face by a trained researcher (M.A.H.) using a validated questionnaire. Participants were required to answer 22 questions concerning knowledge of breast cancer and 5 questions on the perception of breast cancer management and treatment outcomes. Results: The mean total score of knowledge was $59.1 \%$, with Indian women having significantly less knowledge than the Chinese and Malay women ( $p<0.001)$. Only $117(32.3 \%)$ and 120 (33.0\%) women were aware of the recommended breast self-examination (BSE) and clinical breast examination (CBE) guidelines, respectively. Multiple regression analysis showed that ethnicity, age, level of education and employment status were major determinants of breast cancer knowledge. Conclusion: The current study has demonstrated that women in the state of Penang have serious knowledge deficits about breast cancer and poor awareness
\end{abstract}

of BSE and CBE guidelines. This study has highlighted the need of an intensive breast cancer awareness campaign which should also stress the importance of early detection and reporting of breast cancer. Copyright $\odot 2009$ S. Karger AG, Basel

\section{Introduction}

Over the past two decades, breast cancer has become an issue of public health concern in developing countries due to its high incidence and associated mortality, especially among women. In 2005, breast cancer caused 502,000 deaths (7\% of cancer deaths; almost $1 \%$ of all deaths) worldwide [1]. Malaysia is a multiethnic developing country, with Malay, Chinese, and Indian ethnic groups being the most common. In Malaysia, breast cancer is the most common cancer among all ethnic groups and the principal cause of cancer death in women, accounting for about $11 \%$ of all medical certified deaths [2]. Although it appears that the incidence of breast cancer in Malaysia is lower than in developed countries, the difference may be attributable to the difficulties in getting accurate data and to underreporting of cases [3]. The age pattern showed a peak age-specific incidence rate for the 50- to 59-year-olds, and then declined in the older wom-

\section{KARGER}

Fax +4161306 1234

E-Mail karger@karger.ch

www.karger.com
(C) 2009 S. Karger AG, Basel

$1011-7571 / 10 / 0191-0061 \$ 26.00 / 0$

Accessible online at:

www.karger.com/mpp
Muhammad Abdul Hadi

Department of Clinical Pharmacy, Faculty of Pharmacy

Universiti Teknologi MARA

40450 Shah Alam, Selangor (Malaysia)

Tel. +60 35544 2736, Fax +60 35544 2725, E-Mail abdulhadi83@gmail.com 
en [4]. The overall age-standardized incidence rate was 46.2 per 100,000 women. The Chinese ethnic group had the highest incidence, with an age-standardized incidence rate of 59.7 per 100,000 population, followed by Indians: 55.8 and Malays: 33.9 per 100,000 population in 2003 [4].

Delayed presentation of symptomatic breast cancer for 3 months or more from the first detection to the time of diagnosis and treatment has been associated with increased tumor size [5] and poor long-term survival $[5,6]$. Approximately, $20-30 \%$ of Caucasian women wait for at least 3 months before seeking help for breast cancer symptoms [7]. In Malaysia, 50-60\% of women present in stages 3 and 4 with little or no benefit to be derived from any form of therapy [8]. A recent decline in deaths from breast cancer has been reported in the Western world due to improved survival from a combination of earlier diagnosis, breast screening and improvement in treatment methods $[9,10]$. Evidence suggests that older women in developed countries are more likely to delay their presentation with breast cancer, although evidence of influence of other demographic and behavioral factors on the delayed presentation remains inadequate [11]. In developing countries, it is suggested that negative sociocultural perception of breast cancer, strong beliefs in traditional medicine and perhaps strong religious beliefs are the main reasons for the delay in presentation $[12,13]$. There are also data suggesting that factors related to women's knowledge and beliefs about breast cancer and its management may contribute significantly to medical help-seeking behaviors [14]. Understanding the factors that influence patients' delay in seeking breast cancer treatment is therefore necessary to improve its treatment outcomes.

Since breast cancer is a global health care concern, several studies have been conducted worldwide to elicit women's knowledge and beliefs about breast cancer [1519]. However, to the best of our knowledge, no such studies have been reported in the Malaysian population. It is therefore necessary to examine the differences in knowledge and perception of breast cancer among women living in a country of wide cultural diversities. Hence, we conducted a cross-sectional survey among women in the state of Penang in an effort to expand our current knowledge of what women of various ethnic groups know and perceive about breast cancer and what sociodemographic factors might influence the knowledge and perceptions. Gathering baseline data on women's knowledge is essential in developing an effective and targeted educational campaign to prevent delayed presentation and increase adherence to treatment regimens of breast cancer.

\section{Subjects and Methods}

\section{Study Design and Population}

A cross-sectional survey was conducted from February 5 to March 15, 2008 in the state of Penang, Malaysia. The minimum effective sample size was estimated to be 384 using the online sample size calculator Raosoft ${ }^{\circledR}[20]$ with a confidence interval of 95 and 5\% margin of error. Due to lack of sampling frame and upto-date electronic population database, a convenient sampling technique was used. Penang is the 8th most populous state of Malaysia, with the Chinese ethnic group as the majority (42.6\%), followed by Malay (41\%) and Indian (9.9\%) [21]. There are 6 government-owned general hospitals and 16 private hospitals in addition to 62 rural clinics and 8 private maternity homes. As of 2007, the physician-to-population ratio was 1:996. For the study sites, Penang was divided into two regions, and two shopping malls were selected from each region. A total of 600 women of various ethnic groups were initially approached, but only 400 gave verbal consent for participation. Data from 22 participants were incomplete and therefore excluded from the analysis. Women were asked about their personal history of breast cancer before they were recruited into the study, which included women above 15 years of age with no personal history of breast cancer and the ability to understand the questionnaire.

\section{Data Collection}

Each participant was interviewed face-to-face by a trained researcher (M.A.H.) using a validated questionnaire. The questionnaire was designed to obtain information on sociodemographic characteristics and knowledge and perception of breast cancer. It was developed based on information drawn from the literature on risk factors, signs and symptoms, and common methods for early detection of breast cancer. Questions on the perception of breast cancer were adapted and modified from a study by Grunfeld et al. [15]. A five-point Likert-type scale (from strongly agree to strongly disagree) was used to elicit the perception of the women towards management and treatment outcomes of breast cancer. Developed in the English language, the questionnaire was then translated into Malay, which is the national language of Malaysia. The translation was validated using the standard forward and backward method. Face and content validation was done by the two senior faculty members (M.A.A.H., A.A.S.), an oncologist (E.M.M.) and an oncology pharmacist (T.J.K.). The questionnaire was pretested on a convenient sample of 30 women (not included in the final sample) drawn from the target population. In addition to questions on sociodemographic characteristics (age, level of education, monthly income, employment status and race), the final instrument had 27 items and was divided into 4 parts: general knowledge of breast cancer: 4 questions; knowledge of risk factors: 10 questions; knowledge of symptoms and screening tests: 8 questions; perception towards the management and treatment outcomes of breast cancer: 5 questions. Participants were awarded one point for each correct response and zero points for each wrong or 'do not know' response on items related to knowledge. The maximum score was 22 since questions on perception of the management and treatment outcomes of breast cancer were not scored. 
Table 1. Sociodemographic data of study participants by ethnicity $(\mathrm{n}=363)$

\begin{tabular}{|c|c|c|c|c|c|}
\hline Variables & $\begin{array}{l}\text { Total } \\
(\mathrm{n}=363)\end{array}$ & $\begin{array}{l}\text { Malays } \\
(\mathrm{n}=177)\end{array}$ & $\begin{array}{l}\text { Chinese } \\
(\mathrm{n}=121)\end{array}$ & $\begin{array}{l}\text { Indian } \\
(n=65)\end{array}$ & $\mathrm{p}$ value \\
\hline Age & $30.9 \pm 9.7$ & $30.6 \pm 9.1$ & $30.0 \pm 9.8$ & $33.0 \pm 11.2$ & $0.2^{1}$ \\
\hline $19-24$ & $118(32.5)$ & $52(29.4)$ & $51(42.1)$ & $15(23.1)$ & \\
\hline $25-34$ & $147(40.5)$ & $77(43.5)$ & $41(33.9)$ & $29(44.6)$ & \\
\hline $35-44$ & $51(14.0)$ & $27(15.3)$ & $15(12.4)$ & $9(13.8)$ & \\
\hline $45-54$ & $35(9.6)$ & $18(10.2)$ & $11(9.1)$ & $6(9.2)$ & \\
\hline $55-60$ & $12(3.3)$ & $3(1.7)$ & $3(2.5)$ & $6(9.2)$ & \\
\hline Education level & & & & & $<0.001^{2}$ \\
\hline No education & $5(1.3)$ & $0(0.0)$ & $1(0.8)$ & $4(6.2)$ & \\
\hline Primary & $9(2.4)$ & $3(1.7)$ & $2(1.7)$ & $4(6.2)$ & \\
\hline Secondary & $86(23.7)$ & $55(31.1)$ & $16(13.2)$ & $15(23.1)$ & \\
\hline Diploma & $91(25.1)$ & $51(28.8)$ & $21(17.4)$ & $19(29.2)$ & \\
\hline University & $172(47.4)$ & $68(38.4)$ & $81(66.9)$ & $23(35.4)$ & \\
\hline Employment status & & & & & $0.2^{2}$ \\
\hline Unemployed/student & $100(27.5)$ & $34(19.2)$ & $45(37.2)$ & $21(32.3)$ & \\
\hline Government & $177(48.7)$ & $121(68.4)$ & $41(33.9)$ & $15(23.1)$ & \\
\hline Private & $71(19.5)$ & $20(11.3)$ & $27(22.3)$ & $24(36.9)$ & \\
\hline Retired & $4(1.1)$ & $1(0.6)$ & $2(1.7)$ & $1(1.5)$ & \\
\hline Self-employed & $11(3.0)$ & $1(0.6)$ & $6(5.0)$ & $4(6.2)$ & \\
\hline Monthly income $\mathrm{e}^{3}$ & & & & & $0.5^{2}$ \\
\hline None & $94(25.8)$ & $29(16.4)$ & $41(33.9)$ & $24(36.9)$ & \\
\hline$<$ RM 1,000 & $38(10.4)$ & $25(14.1)$ & $7(5.8)$ & $6(9.2)$ & \\
\hline RM 1,000-3,000 & $175(48.2)$ & $105(59.3)$ & $49(40.5)$ & $21(32.3)$ & \\
\hline$>$ RM 3,000 & $56(15.4)$ & $18(10.2)$ & $24(19.8)$ & $14(21.5)$ & \\
\hline
\end{tabular}

Figures in parentheses are percentages.

${ }^{1}$ Assessed by one-way ANOVA. ${ }^{2}$ Assessed by the Kruskal-Wallis test. ${ }^{3} 1$ Malaysia ringgit $(\mathrm{RM})=0.28$ USD.

Data Analysis

All data were analyzed using the Statistical Package for the Social Sciences (SPSS Inc., Chicago, Ill., USA) version 15.0 and Microsoft Excel. The Kruskal-Wallis test and one-way ANOVA with post hoc Tukey HSD (honestly significant difference: a post hoc analysis used for multiple comparisons in order to detect whether or not differences between pair-wise groups exist) were used wherever appropriate. The level of statistical significance was set at $\mathrm{p}<0.05$.

\section{Results}

\section{Sociodemographic Distribution of Study Participants}

The sociodemographic characteristics of the study participants are presented in table 1: Malay: 177 (48.8\%), Chinese: 121 (33.3\%) and Indian: 65 (17.1\%). These groups constitute the majority (95\%) of the Penang population. There were no significant differences between the ethnic groups for mean age, employment status, and monthly income. However, there was a significant difference in
Table 2. Knowledge score of various ethnic groups

\begin{tabular}{|c|c|c|c|c|c|c|}
\hline \multirow{2}{*}{$\begin{array}{l}\text { Knowl } \\
\text { edge } \\
\text { score }\end{array}$} & \multirow{2}{*}{$\begin{array}{l}\text { Max. } \\
\text { possible } \\
\text { score }\end{array}$} & \multicolumn{4}{|c|}{ Score mean $\pm \mathrm{SD}$} & \multirow{2}{*}{$\begin{array}{l}\mathrm{p} \\
\text { value }^{1}\end{array}$} \\
\hline & & total & Malay & Chinese & Indian & \\
\hline GK & 4 & $1.8 \pm 0.7$ & $1.9 \pm 0.6$ & $2.0 \pm 0.7$ & $1.5 \pm 1.0$ & $<0.001$ \\
\hline RF & 10 & $5.3 \pm 2.3$ & $5.6 \pm 2.2$ & $5.7 \pm 2.3$ & $4.5 \pm 2.5$ & $<0.001$ \\
\hline SS & 8 & $5.4 \pm 2.3$ & $5.9 \pm 1.9$ & $5.8 \pm 2.9$ & $4.6 \pm 2.2$ & $<0.001$ \\
\hline TS & 22 & $12.6 \pm 4.1$ & $13.6 \pm 3.5$ & $13.6 \pm 4.2$ & $10.6 \pm 4.7$ & $<0.001$ \\
\hline
\end{tabular}

1 The difference between the ethnic groups was assessed by one-way ANOVA. GK = General knowledge; $\mathrm{RF}=$ risk factor; $\mathrm{SS}=$ symptoms and screening; $\mathrm{TS}=$ total score.

the level of education among the ethnic groups, with the Chinese group having the highest proportion of university graduates (67\%), followed by the Malay group (38\%). The mean age of the study participants was $30.9 \pm 9.7$ years (range 19-60 years). 172 (47.4\%) participants had 
Table 3. Items measuring respondents' knowledge by domain

\begin{tabular}{|c|c|c|}
\hline Item & Correct & Incorrect \\
\hline \multicolumn{3}{|l|}{ General knowledge } \\
\hline Only females are affected by breast cancer & $269(74.1)$ & $94(25.9)$ \\
\hline Breast cancer can be transmitted from one person to another & $323(88.9)$ & $40(11.1)$ \\
\hline Breast cancer is the leading cause of death in Malaysian women & $55(15.2)$ & $308(84.8)$ \\
\hline The estimated life time risk of developing breast cancer in Malaysian women is? & $38(10.5)$ & $325(89.5)$ \\
\hline \multicolumn{3}{|l|}{ Knowledge of breast cancer risk factors } \\
\hline Family history of breast cancer & $294(80.1)$ & $69(19.9)$ \\
\hline Cigarette smoking & $273(75.2)$ & $90(24.8)$ \\
\hline Low-fat diet & $178(49.0)$ & $185(51.0)$ \\
\hline First child after the age of 30 years & $170(46.9)$ & $193(53.1)$ \\
\hline Early onset of menses (before the age of 12 years) & $116(31.9)$ & $247(68.1)$ \\
\hline Late menopause (after the age of 55 years) & $109(30.0)$ & $254(70.0)$ \\
\hline Painless breast lump & $117(32.2)$ & $246(67.8)$ \\
\hline Lump under armpit & $267(73.5)$ & $96(26.5)$ \\
\hline Nipple discharge & $262(72.1)$ & $101(27.9)$ \\
\hline Change in breast shape & $284(78.2)$ & $79(21.8)$ \\
\hline Pain in breast region & $285(78.5)$ & $78(21.5)$ \\
\hline Dimpling of breast skin & $219(60.3)$ & $144(39.7)$ \\
\hline BSE is recommended for females once a month & $117(32.3)$ & $246(67.7)$ \\
\hline $\mathrm{CBE}$ is recommended for females once a year & $120(33.0)$ & $243(67.0)$ \\
\hline
\end{tabular}

Figures in parentheses are percentages.

university education, whereas 91 (25.1\%) and 86 (23.7\%) participants had diploma and secondary school education, respectively. About half (48.7\%) of the respondents were employed in the government sector compared to $19.5 \%$ in the private sector, and more than two-thirds of the government employees were Malay.

\section{Knowledge of Breast Cancer}

The overall mean total score of breast cancer knowledge was $13.0 \pm 4.0$. There was a significant difference in mean total score of breast cancer knowledge among the ethnic groups (table 2). Post hoc analysis (Tukey HSD) showed that Indians had significantly less knowledge compared to Malay $(\mathrm{p}<0.001)$ and Chinese $(\mathrm{p}<0.001)$. The analysis further showed that the Indians had significantly less knowledge in all 3 knowledge domains, including general knowledge, breast cancer risk factors, symptoms and screening tests. However, there was no significant difference in the mean total score of knowledge between Chinese and Malay ethnic groups ( $\mathrm{p}=$ 1.000).
The large majority, 308 (84.8\%) women, wrongly believed that breast cancer was the leading cause of death among women, and only 38 (10.5\%) correctly recognized the estimated lifetime risk of developing breast cancer to be 1 in 19 in Malaysian women (table 3). More than twothirds of the study participants acknowledged family history, old age and cigarette smoking as potential risk factors for breast cancer. Furthermore, a major proportion of women were unable to appreciate complex risk factors associated with breast cancer such as menopause after the age of 55 years: 254 (70.0\%); early onset of menses before the age of 12 years $247(68.1 \%)$ and first child birth after 30 years of age 193 (53.1\%). 246 (67.8\%) and 144 (39.7\%) of the participants failed to recognize painless breast lump and dimpling of breast skin as potential symptoms of breast cancer, respectively. Pain in breast region (285; $78.5 \%)$ and change in breast shape $(284 ; 78.2 \%)$ were the most frequently correctly identified symptoms. Surprisingly, only 117 (32.3\%) women were aware of the recommendations for practicing breast self-examination (BSE) and $120(33.0 \%)$ for clinical breast examination (CBE). 
Table 4. Distribution of breast cancer knowledge according to sociodemographic variables

\begin{tabular}{|c|c|c|c|c|}
\hline Variables & $\mathrm{n}$ & $\begin{array}{l}\text { Mean total } \\
\text { knowledge } \\
\text { score } \pm \mathrm{SD}\end{array}$ & d.f. & $\begin{array}{l}\mathrm{p} \\
\text { value }^{1}\end{array}$ \\
\hline \multicolumn{5}{|l|}{ Age } \\
\hline $19-24$ & 118 & $13.9 \pm 3.1$ & 4 & $<0.001$ \\
\hline $25-34$ & 147 & $12.9 \pm 4.1$ & & \\
\hline $35-44$ & 51 & $11.7 \pm 4.7$ & & \\
\hline $45-54$ & 35 & $13.2 \pm 4.7$ & & \\
\hline $55-60$ & 12 & $9.5 \pm 5.4$ & & \\
\hline \multicolumn{5}{|l|}{ Education level } \\
\hline No education & 5 & $9.8 \pm 5.7$ & 4 & $<0.001$ \\
\hline Primary & 9 & $8.4 \pm 2.6$ & & \\
\hline Secondary & 86 & $11.5 \pm 4.1$ & & \\
\hline Diploma & 91 & $13.1 \pm 4.0$ & & \\
\hline University & 172 & $13.9 \pm 3.8$ & & \\
\hline \multicolumn{5}{|l|}{ Employment status } \\
\hline Unemployed/student & 100 & $12.8 \pm 3.9$ & 4 & $<0.001$ \\
\hline Government & 177 & $14.2 \pm 3.6$ & & \\
\hline Private & 71 & $11.1 \pm 4.1$ & & \\
\hline Retired & 4 & $11.8 \pm 6.1$ & & \\
\hline Self-employed & 11 & $8.2 \pm 4.8$ & & \\
\hline \multicolumn{5}{|l|}{ Monthly income ${ }^{2}$} \\
\hline None & 94 & $12.6 \pm 4.2$ & 4 & $<0.001$ \\
\hline$<$ RM 1,000 & 38 & $12.8 \pm 3.5$ & & \\
\hline RM 1,000-3,000 & 175 & $13.2 \pm 4.1$ & & \\
\hline$>$ RM 3,000 & 56 & $13.2 \pm 4.6$ & & \\
\hline
\end{tabular}

${ }^{1}$ The difference of mean total knowledge score was assessed using one-way ANOVA. ${ }^{2} 1$ Malaysia ringgit $(\mathrm{RM})=0.28 \mathrm{USD}$.

Age, educational level and social status significantly influenced breast cancer knowledge (table 4). University degree holders scored considerably better than those who had primary or secondary level of education $(p<0.001)$. Employees of the government sector had appreciably more knowledge than the unemployed and employees of the private sector $(\mathrm{p}<0.001)$. Based on multivariate analysis, ethnicity, education level and employment status were the most important predictors of breast cancer knowledge and could explain about $81 \%$ of the variation in the respondents' total knowledge of breast cancer $\left(\mathrm{R}^{2}=0.81, \mathrm{p}<0.001\right)$.

Further categorization of degree of knowledge using an arbitrary scoring scale developed from the literature, shown in table 5 , revealed that about $25 \%$ of Chinese, $18 \%$ of Malay and only $9 \%$ of Indians had good knowledge of breast cancer. Less than $1 \%$ of the participants had very good knowledge and about $30 \%$ of the study population had poor to very poor knowledge.

Knowledge and Perception of Breast Cancer
Table 5. Status of knowledge

\begin{tabular}{lllllr}
\hline $\begin{array}{l}\text { Total } \\
\text { score }\end{array}$ & $\begin{array}{l}\text { Status of } \\
\text { knowledge }\end{array}$ & $\begin{array}{l}\text { Malay } \\
(\mathrm{n}=177)\end{array}$ & $\begin{array}{l}\text { Chinese } \\
(\mathrm{n}=121)\end{array}$ & $\begin{array}{l}\text { Indian } \\
(\mathrm{n}=65)\end{array}$ & $\begin{array}{l}\text { Total } \\
(\mathrm{n}=363)\end{array}$ \\
\hline$\leq 7$ & very poor & $12(6.8)$ & $10(8.3)$ & $16(24.6)$ & $38(10.5)$ \\
$8-11$ & poor & $31(17.5)$ & $20(16.5)$ & $22(33.8)$ & $73(20.1)$ \\
$12-16$ & moderate & $103(58.2)$ & $60(49.6)$ & $20(30.8)$ & $183(50.4)$ \\
$17-20$ & good & $30(16.9)$ & $30(24.8)$ & $6(9.2)$ & $66(18.2)$ \\
$>20$ & very good & $1(0.6)$ & $1(0.8)$ & $1(1.5)$ & $3(0.8)$ \\
\hline
\end{tabular}

Figures in parentheses are percentages.

\section{Perception of Management and Treatment Outcomes of Breast Cancer}

More than half of the participants (63\%) believed that women can enjoy a good quality of life after receiving the treatment for breast cancer (table 6). About two thirds of the respondents did not believe that breast cancer treatment results in loss of physical beauty. However, more than $60 \%$ agreed that the treatment is a long and painful process.

\section{Discussion}

Our findings confirmed previous reports $[8,16-18]$ that the deficit in knowledge of symptoms and risk factors were the reasons for the delayed presentation of breast cancer in many developing countries such as Pakistan [16], Iran [17] and Nigeria [18]. However, in developed nations where there is a diminution in mortality secondary to early detection and improved treatment modalities $[10,11]$, delayed presentation remains a problem for older women as seen in British [15], American [19], and Australian women [22]. It has been reported that older adults should not be expected to seek medical help despite symptoms of disease, since these symptoms may not cause them any pain or affect their functioning [23]. It is also noteworthy that women in the older age group, who are at increased risk of developing breast cancer, lack sufficient knowledge about risk factors and symptoms of breast cancer.

In the present survey, most women were not aware of BSE and CBE, which is consistent with the findings of another Malaysian study [24], in which only $24.4 \%$ of women practiced BSE once a month and $18.4 \%$ had a Pap smear examination within the last 3 years. The Malaysian Ministry of Health promotes the practice of monthly BSE for women above the age of 20 years and annual CBE by med- 
Table 6. Perception towards management and treatment outcomes of breast cancer

\begin{tabular}{|c|c|c|c|c|c|}
\hline Item & SA & A & $\mathrm{N}$ & DA & SDA \\
\hline $\begin{array}{l}\text { A woman after receiving treatment for breast cancer can enjoy a } \\
\text { good quality of life }\end{array}$ & $56(15.4)$ & $174(47.9)$ & $85(23.4)$ & $36(9.91)$ & $12(3.3)$ \\
\hline The treatment for breast cancer is a long and painful process & $55(15.1)$ & $169(46.5)$ & $87(23.9)$ & $46(12.6)$ & $6(1.6)$ \\
\hline Treatments for breast cancer are more helpful to young people & $40(11.0)$ & $140(38.6)$ & $84(23.1)$ & $92(25.3)$ & $7(1.9)$ \\
\hline Treatment for breast cancer is embarrassing & $5(1.4)$ & $32(8.8)$ & $64(17.6)$ & $170(46.8)$ & $92(25.3)$ \\
\hline Treatment of breast cancer results in loss of physical beauty & $47(12.9)$ & $112(30.8)$ & $82(22.6)$ & $87(24.0)$ & $35(9.6)$ \\
\hline
\end{tabular}

Figures in parentheses are percentages. $\mathrm{SA}=$ Strongly agree; $\mathrm{A}=$ agree; $\mathrm{N}=$ neutral; $\mathrm{DA}=$ disagree; $\mathrm{SDA}=$ strongly disagree.

ical or paramedical personnel [2]. There is consistent evidence in the literature that $\mathrm{CBE}$ and mammography can reduce mortality due to early detection and treatment of breast cancer [25]. On the other hand, the effectiveness of BSE in reducing mortality is controversial since clinical trials $[26,27]$ did not find any evidence that practicing it is beneficial in reducing mortality. Instead, a higher rate of physician visits, increased level of anxiety and benign biopsies with consequent use of health resources were observed in women who were taught BSE [26]. However, some scholars argue that practicing BSE make women more 'breast aware' and consequently more liable to detect tumors since many breast tumors are discovered by women themselves [28]. In developing countries like Malaysia, where there is no nationwide population-based breast screening mammography program [8] due to limited resources, BSE is considered to be a simple, inexpensive, noninvasive, and nonhazardous intervention, which is not only acceptable, cost-effective and appropriate, but also encourages women to take an active responsibility in preventive health [2].

Among the risk factor assessed in this study, family history of breast cancer was the most commonly identified risk factor, consistent with a recent cross-sectional study of knowledge and belief conducted among British women [15]. Similarly, women in the British study were unable to appreciate complex risk factors such as early onset of menses and late menopause. Our findings that older women had poorer knowledge of breast cancer risk factors and symptoms confirmed the previous studies in the USA [19] and Australia [22]. Women aged 55 and above in this survey had significantly less knowledge than those of younger age groups. However, in contrast to findings of Grunfeld et al. [15], a majority of the respondents in our survey failed to recognize a painless breast lump as one of the symptoms of breast cancer. Rec- ognizing the whole range of breast cancer symptoms is essential for early self-detection and treatment of breast cancer.

The vast majority of our study participants had correct beliefs about breast cancer management and its outcomes. They, however, had a negative perception of breast cancer treatment by considering it to be a long-term and painful process. The poor level of knowledge and lack of awareness about the screening tests can partly explain the delay in presentation of symptomatic breast cancer to a health care provider that is a common occurrence among Malaysian women.

The results of this survey suggest the need for educational programs as tools for improving the current knowledge of breast cancer, targeting women through the mass media and perhaps clinical settings. The programs should also emphasize the need for prevention of breast cancer by avoiding exposure to potential carcinogens such as frequent exposure to X-rays and cigarette smoke, and by promoting healthy diets that are rich in fiber and contain less saturated fat, in addition to physical exercise. Television, radio broadcasts and distribution of leaflets should be used to disseminate the required information pertaining to breast cancer. Although television and radio appear to be better media to reach a wider audience, their benefits may be limited only to people who have access to them. Available data suggest that people prefer to learn about cancer-related issues from their doctors and health organizations. Therefore, proper counseling should be done by health care providers within hospitals and clinics to improve breast cancer knowledge, and in this setting leaflets may be an effective tool. The primary goal is to improve the survival rate by promoting early detection and medical help-seeking behaviors among women. 


\section{Limitations of the Study}

The generalizability of the findings from this study must be viewed within the context that this was a convenient sample that may be biased towards more educated, well-informed, and privileged socioeconomic status. Therefore, these findings may not necessarily reflect those of the general population. Nevertheless, an effort was made to ensure that people from all walks of life were well represented in the sample.

\section{Conclusions}

Women in Penang, Malaysia, generally had limited knowledge of risk factors and symptoms of breast cancer, particularly Indians in comparison to Chinese and Malay. Age, educational level and employment status significantly influenced breast cancer knowledge. Ethnicity, employment status, and educational level were the strongest predictors of breast cancer knowledge. This situation demands that awareness about breast cancer among the less educated and less privileged population should be improved through a planned and targeted program.

\section{References}

1 World Health Organization (WHO): Cancer fact sheet No. 297, 2006; available at http:// www.who.int/mediacentre/factsheets/fs297/ en/index.html (accessed 2007-09-15).

2 Narimah A, Rugayah HB, Tahir A, Maimunah AH: Breast Examination, National Health and Morbidity Survey 1996, vol 20. Kuala Lumpur, Public Health Institute, Ministry of Health, 1999.

- 3 Hisham AN, Yip CH: Spectrum of breast cancer in Malaysian women. World J Surg 2003;27:921-923.

4 National Cancer Registry: Second report on cancer incidence in Malaysia 2003; available at www.radiologymalaysia.org/Archive/ NCR/2ndNCR.pdf (accessed 2007-09-5).

$\checkmark 5$ Richards MA, Smith P, Ramirez AJ, Fentiman IS, Rubens RD: The influence on survival of delay in the presentation and treatment of symptomatic breast cancer. $\mathrm{Br} \mathrm{J}$ Cancer 1999;79:858-864.

6 Rossi S, Cinini C, Di Pietro C, Lombardi CP, Crucitti A, Bellantone R, Crucitti F: Diagnostic delay in breast cancer: correlation with disease stage and prognosis. Tumori 1990;76:559-562.

7 Richards MA, Westcombe AM, Love SB, Littlejohns P, Ramirez AJ: Influence of delay on survival in patients with breast cancer: a systematic review. Lancet 1999;353:1119-1126.

$\checkmark$ Hisham AN, Yip CH: Overview of breast cancer in Malaysian women: a problem with late diagnosis. Asian J Surg 2004;27:130133.

9 Richards MA, Stockton D, Babb P, Coleman MP: How many deaths have been avoided through improvements in cancer survival? BMJ 2000;320:895-898.
10 Peto R, Boreham J, Clarke M, Davies C, Beral $\mathrm{V}$ : UK and USA breast cancer deaths down $25 \%$ in year 2000 at ages $20-69$ years. Lancet 2000;355:1822.

- 11 Ramirez AJ, Westcombe AM, Burgess CC, Sutton S, Johns LP, Richards MA: Factors predicting delayed presentation of symptomatic breast cancer: a systematic review. Lancet 1999;353:1127-1131.

12 Rashidi A, Rajaram SS: Middle Eastern Asian Islamic women and breast self-examination. Needs assessment. Cancer Nurs 2000;23:64-70.

13 Rajaram SS, Rashidi A: Asian-Islamic women and breast cancer screening: a socio-cultural analysis. Women Health 1999;28:45-48.

14 Odusanya OO, Tayo OO: Breast cancer knowledge, attitudes and practice among nurses in Lagos, Nigeria. Acta Oncol 2001; 40:844-848.

15 Grunfeld EA, Ramirez AJ, Hunter MS, Richards MA: Women's knowledge and beliefs regarding breast cancer. Br J Cancer 2002;86: 1373-1378.

16 Usmani K, Khanum A, Afzal H, Ahmad N: Breast cancer in Pakistani women. J Environ Pathol Toxicol Oncol 1996;15:251-253.

17 Harirchi I, Ebrahimi M, Zamani N, Jarvandi S, Montazeri A: Breast cancer in Iran: a review of 903 case records. Public Health 2000; 114:143-145.

18 Okobia MN, Bunker CH, Okonofua FE, Osime U: Knowledge, attitude and practice of Nigerian women towards breast cancer: a cross-sectional study. World J Surg Oncol 2006;4:11.

19 Breslow RA, Sorkin JD, Frey CM, Kessler LG: American's knowledge of cancer risk and survival. Prev Med 1997;26:170-177.
20 Raosoft $^{\circledR}$. An online sample size calculator available at http://www.ezsurvey.com/samplesize.html (accessed 2007-09-15).

21 Department of Statistics: Malaysia Year Book of Statistics 2007. Kuala Lumpur, Department of Statistics Malaysia, 2007.

-22 Paul C, Barratt A, Redman S, Cockburn J, Lowe J: Knowledge and perceptions about breast cancer incidence, fatality and risk among Australian women. Aust NZ J Public Health 1999;23:396-400.

23 Ford G, Taylor R: The elderly as under consulters: a critical reappraisal. J R Coll Gen Pract 1985;35:244-247.

24 Chee HL, Rashidah S, Shamsuddin K, Intan $\mathrm{O}$ : Factors related to the practice of breast self-examination (BSE) and Pap smear screening among Malaysian women workers in selected electronics factories. BMC Womens Health 2003;3:3.

25 Dbameharha YA: Knowledge about breast cancer and mammography in breast cancer screening among women awaiting mammography. Turk J Med Sci 2005;35:35-42.

26 Baxter N; Canadian Task Force on Preventive Health Care: Preventive health care, 2001 update: should women be routinely taught breast self-examination to screen for breast cancer? CMAJ 2001;164:1837-1846.

27 Thomas DB, Gao DL, Ray RM, Wang WW, Allison CJ, Chen FL, Porter P, Hu YW, Zhao GL, Pan LD, Li W, Wu C, Coriaty Z, Evans I, Lin MG, Stalsberg H, Self SG: Randomized trial of breast self-examination in Shanghai: final results. J Natl Cancer Inst 2002;94: 1445-1457.

28 Larkin M: Breast self examination does more harm than good, says task force. Lancet 2001; 357:2109. 